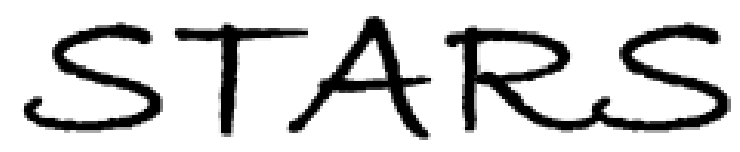

University of Central Florida

STARS

$1-1-2010$

\title{
Using SPOT-VGT NDVI as a successive ecological indicator for understanding the environmental implications in the Tarim River Basin, China
}

Zhandong Sun

Ni-Bin Chang

University of Central Florida

Christian Opp

Find similar works at: https://stars.library.ucf.edu/facultybib2010

University of Central Florida Libraries http://library.ucf.edu

This Article is brought to you for free and open access by the Faculty Bibliography at STARS. It has been accepted for inclusion in Faculty Bibliography 2010s by an authorized administrator of STARS. For more information, please contact STARS@ucf.edu.

\section{Recommended Citation}

Sun, Zhandong; Chang, Ni-Bin; and Opp, Christian, "Using SPOT-VGT NDVI as a successive ecological indicator for understanding the environmental implications in the Tarim River Basin, China" (2010). Faculty Bibliography 2010s. 849.

https://stars.library.ucf.edu/facultybib2010/849

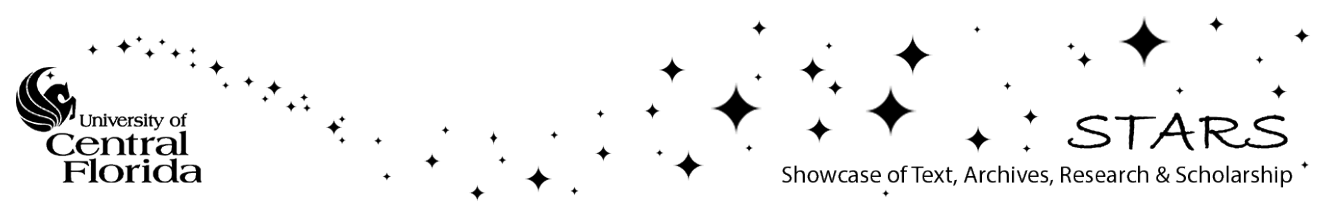




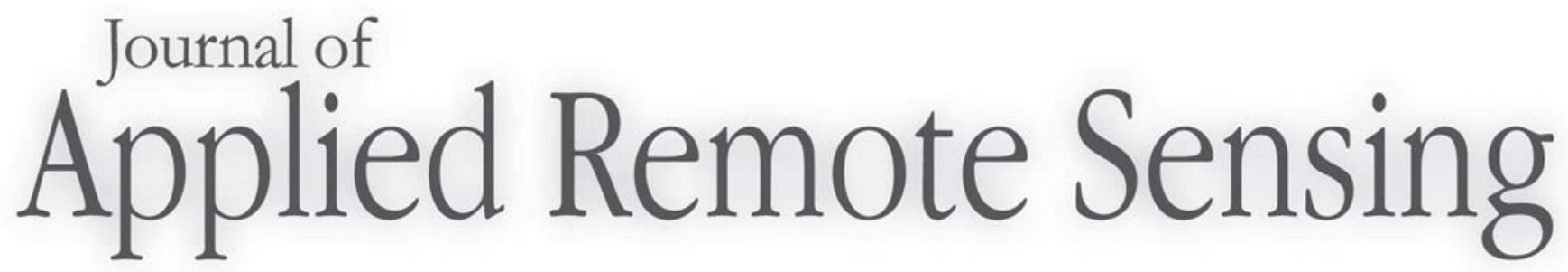

\section{Using SPOT-VGT NDVI as a successive ecological indicator for understanding the environmental implications in the Tarim River Basin, China}

Zhandong Sun

Ni-Bin Chang

Christian Opp 


\title{
Using SPOT-VGT NDVI as a successive ecological indicator for understanding the environmental implications in the Tarim River Basin, China
}

\author{
Zhandong Sun ${ }^{\mathrm{a}}$, Ni-Bin Chang ${ }^{\mathrm{b}}$, and Christian Opp ${ }^{\mathrm{c}}$ \\ ${ }^{a}$ Nanjing Institute of Geography and Limnology, Chinese Academy of Science, State Key \\ Laboratory of Lake Science and Environment, Nanjing 210008 China \\ sun@niglas.ac.cn \\ ${ }^{\mathrm{b}}$ University of Central Florida, Department of Civil, Environmental, and Construction \\ Engineering, Orlando, Florida 32816 USA \\ nchang@mail.ucf.edu \\ c University of Marburg, Faculty of Geography, Marburg, D-35032 Germany \\ opp@staff.uni-marburg.de
}

\begin{abstract}
The resilience and vulnerability of terrestrial ecosystem in the Tarim River Basin, Xinjiang is critical in sustainable development of the northwest region in China. To learn more about causes of the ecosystem evolution in this wide region, vegetation dynamics can be a surrogate indicator of environmental responses and human perturbations. This paper aims to use the inter-annual and intra-annual coefficient of variation $(\mathrm{CoV})$ derived by the SPOTVGT Normalized Difference Vegetation Index (NDVI) as an integrated measure of vegetation dynamics to address the environmental implications in response to climate change. To finally pin down the vegetation dynamics, the intra-annual CoV based on monthly NDVI values and the inter-annual $\mathrm{CoV}$ based on seasonally accumulated NDVI values were respectively calculated. Such vegetation dynamics can then be associated with precipitation patterns extracted from the Tropical Rainfall Measuring Mission (TRMM) data and irrigation efforts reflecting the cross-linkages between human society and natural systems. Such a remote sensing analysis enables us to explore the complex vegetation dynamics in terms of distribution and evolution of the collective features of heterogeneity over local soil characteristics, climate change impacts, and anthropogenic activities at differing space and time scales. Findings clearly indicate that the vegetation changes had an obvious trend in some high mountainous areas as a result of climate change whereas the vegetation changes in fluvial plains reflected the increasing evidence of human perturbations due to anthropogenic activities. Some possible environmental implications were finally elaborated from those crosslinkages between economic development and resources depletion in the context of sustainable development.
\end{abstract}

Keywords: Ecological indicator, Tarim Basin, vegetation dynamics, coefficient of variation, SPOT-VGT NDVI, climate change, Tropical Rainfall Measuring Mission (TRMM), sustainable development.

\section{INTRODUCTION}

Global climate change and economic development may have caused salient impacts on the resilience and vulnerability of terrestrial ecosystem $[1,2]$. With this concern, two mainstreams of research in earth system science have centered at Global Change and Terrestrial Ecosystem (GCTE) and Land-Use and Land-Cover Change (LUCC) in the International GeosphereBiosphere Programme (IGBP) [3]. Both emphasize the integrated studies of coupled human 
and natural systems to improve the understanding necessary to respond to global climate changes.

Vegetation changes, as an important component of terrestrial ecosystems, may become such an ecological index via coupling the phenological effects and the anthropogenic impacts on a long-term basis [4]. It is evident that recent climatic changes have already affected species physiology, distribution, and phenology [5]. Causal attribution of recent biological trends to climate changes is complicated by non-climatic influences that dominate local, short-term biological changes [6]. This phenomenon is especially relevant in arid regions which cover about $45 \%$ of Earth's land surface; yet their ecosystem dynamics have been overlooked for a long time partly because arid ecosystems seem to have low rates of biological activities as the result of sparse biota [7]. However, Rotenberg and Yakir indicated that the dryland Yatir Forest in Israel can take up carbon at rates similar to those of pine forests in continental Europe [8]. Overall, arid ecosystems are very sensitive to a variety of physical, chemical and biological degradation processes [9]. These types of ecosystems are vulnerable due to poor water availability, and the spatial-temporal dynamics of vegetation are therefore largely impacted [10].

The Tarim River Basin, which is the biggest endorheic basin in Central Asia, can be considered as one of the least water-endowed regions in the world. There are a variety of vegetation types in the Tarim River Basin, caused primarily by regional, geologic, topographic, anthropogenic and climatic differences. Studies showed that climate conditions favor more river runoff during the past decade $[11,12]$. But the water scarcity in the Tarim River has been exacerbated due to the growing water demand driven by population increase and agricultural development in the last decade $[13,14]$. This makes the terrestrial vegetation dynamics of particular significance in terms of plant phenology, soil degradation and organic dynamics [15]. Improvements in the understanding of these factors can certainly provide better environmental management [16].

Remote sensing has obvious advantage in large-scale vegetation cover monitoring [17]. Multitemporal change detection with the aid of remote sensing data can be carried out by simple overlay of classified maps [18]. Vegetation indices have been developed to qualitatively and quantitatively assess vegetation cover using spectral measurements [19]. There are over thirty five vegetation indices that may be applied in different studies $[17,19$, 20]. Yet each type of vegetation index has its own strength and weakness. For instance, the Ratio Vegetation Index (RVI) is the ratio of the near-infrared band divided by the red band that is popular in agricultural monitoring $[19,20]$. The Near Infrared (NIR) increases with increasing canopy, whereas the red decreases with decreasing canopy. Hence, the RVI can be defined as NIR/Red (Landsat: Band 4/Band 3) such that brighter pixels are correlated with more biomass. This index, however, does not perform well when the vegetation cover is less than 50\%; but it is the best choice at the dense vegetation cover [21]. Chlorophyll in actively growing vegetation is a strong absorber of red radiation, and the cell-wall structure of healthy leaves strongly reflects NIR radiation. Therefore, greater photosynthetic activity will result in lower reflectance in the red band and higher reflectance in the NIR. By combining these two spectral regions into a normalized ratio, the sensitivity to photosynthetic activity of vegetation may be enhanced. This ratio is the well-known Normalized Difference Vegetation Index (NDVI), which takes advantage of the spectral response difference of the chlorophyll-loaded vegetal tissues between the red and infra-red channels. The higher the NDVI values, the larger the green vegetation densities are present. The NDVI had been successfully utilized to monitor and assess vegetation covers from regional to global scale [20, 23]. In particular, the NDVI may reduce the effect of sensor degradation by normalizing the spectral bands [22]. It is generally agreed that the NDVI is sensitive to low dense vegetation such as observed in semi-arid areas [24, 25].

Many sensors have the geometric and spectral characteristics associated with different bands to monitor vegetation (e.g., AVHRR, Landsat-TM, SPOT-VGT and MODIS), which 
also results in a substantial interest of assimilating images collected by multiple sensors [2830]. With the aid of AVHRR NDVI time-series, Tucker determined the expansion and contraction of the Sahara Desert [26]. Weiss assessed vegetation changes in Saudi Arabia by means of the coefficient of variation (CoV) of the monthly AVHRR NDVI [27]. Both studies used low resolution NDVI as an ecological indicator for ecosystem health assessment. Despite tremendous achievements, uncertainties and limitations still exist in some areas due to temporal and spatial resolution. The SPOT-4 VEGETATION (VGT) sensor, launched on March 24th, 1998, offers a daily global coverage with a spatial resolution of about $1 \mathrm{~km}^{2}$ possessing spectral bands that can be specifically tailored for monitoring large-area vegetation dynamics [42].

Precipitation impact, a primary driving force influencing vegetation distribution, development, and persistence, is not yet understood well. Characterizing precipitation pattern is the key to assessing the connections between climate change impacts and vegetation dynamics. However, hydrologic data are often lacking, especially in regions with weak infrastructure such as the Tarim River Basin. These areas are sparsely populated and poorly gauged such that the conventional observations are not available to reach sufficient spatial resolution for credible and intensive ecological and societal surveys. Besides, the meteorological observations often vary dramatically over this long period due to spatial climate variability in mountainous areas. Consequently, the hydrometeorological changes can hardly be evaluated properly with local measurements associated with terrain and land use/land cover change (LUCC). Facing such a dilemma, the International Association of Hydrological Sciences (IAHS) has specifically initiated a plan on "Predictions in Ungauged Basins (PUB)" to promote hydrological practices across different terrain, climate and land use and land cover (LULC) [31, 32]. Tropical Rainfall Measuring Mission (TRMM) is the first "space-based rain gauge" that uses microwave radiation to "see" how much precipitation falls from clouds over land and ocean with unparalleled accuracy [33, 34]. TRMM data became available for many studies in regard to regional precipitation patterns in 1998. Since then, TRMM/PR data have been validated and successfully used in many fields $[35,36]$. In view of drought characteristics of the study area, study period, spatial resolution, and linkages with climate changes and anthropogenic perturbations in the past decade [12, 37, 38], the SPOT VGT NDVI data were selected as a means for addressing the precipitation patterns in this study region.

The aim of this paper is to analyze the spatial and temporal patterns of vegetation dynamics and its association with precipitation patterns and anthropogenic perturbations based on NDVI time series and TRMM data. These data were collected by the SPOT VGT sensor and TRMM/PR from 1998 to 2007. Such integration leads to: 1) retrieval of the terrestrial vegetation dynamics and trends, 2) possible investigation of cross-linkages between vegetation dynamics and possible environmental implications, and 3) assessment of the driving forces causing vegetation changes in relation to precipitation patterns and irrigation activities at a large scale in the context of sustainable development.

\section{STUDY AREA}

The Tarim River Basin, with an area $560,000 \mathrm{~km}^{2}$, is the largest inland basins in Central Asia (Fig.1), which has been over-ridden by the Eurasian and Indian continents. The basin is surrounded by high mountains: the Tianshan Mountains to the north, the Himalayan Plateau and Kunlun Mountains to the south, and the Pamir Range to the west. The average height of the mountains exceeds $4,000 \mathrm{~m}$ above sea level. Located at the central region of the basin is the world's second largest active sand desert, the Taklamakan Desert, which covers an area of $338,000 \mathrm{~km}^{2}$ with an elevation ranging from 200 to $1,300 \mathrm{~m}$ [39].

The high mountains and plateaus along the periphery of the Tarim River Basin act as a natural barrier to block the flow with humid moisture into this region. As a consequence, the 
amount and frequency of precipitation are highly variable in space. In the central basin, the average annual precipitation is about $12 \mathrm{~mm}(0.5 \mathrm{inch})$, and is considered as one of the driest regions in the world. The direct effects of precipitation on vegetation growth can be very limited. Along the periphery of the Tarim River Basin, the mean annual precipitation amounts to 50 to $100 \mathrm{~mm}$ ( 2 to 4 inches) in the foothills and neighboring areas. But the slopes of the Tianshan are much wetter and precipitation often exceeds $500 \mathrm{~mm}$ (20 inches). However, annual potential evapotranspiration (PET) may be as high as $2,000-3,000 \mathrm{~mm}$ at many places in this region. The highest and lowest temperatures recorded are $43.6^{\circ} \mathrm{C}$ and $-27.5^{\circ} \mathrm{C}$ in the plain basin, respectively [39].

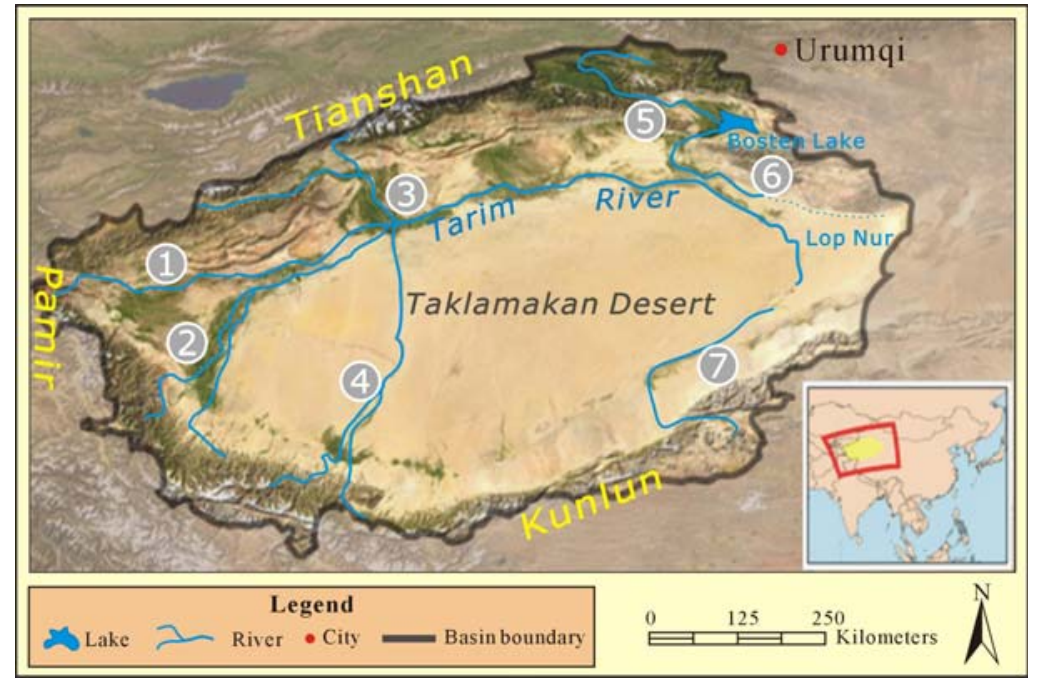

Fig.1. The location and boundary (black line) of the Basin in the Central Asian continent. The major rivers are marked with numbers respectively: (1) Kaxgar, (2) Yarkand, (3) Aksu, (4) Hotan, (5) Kaidu, (6) Kongqi, and (7) Qarqan.

The Tarim River is the principal river of the Xinjiang Uyghur Autonomous Region and is formed by the confluence of the Kaxgar and Yarkand Rivers in the far west. Flowing northeastward from this confluence, the river is then joined some $370 \mathrm{~km}$ (230 miles) downstream by the Aksu and the Hotan Rivers. The Tarim River flows for most of its length through the Taklamakan Desert. The Kaidu River and Lake Bosten are relatively isolated to the northeast. Oasis is a unique landscape due to hydrosphere-desert interaction in arid regions. The natural river dynamics are an important factor in forming the oasis' landscape and the natural river oasis that provides the only possible regeneration sites via seasonal flooding in this region is one of the most unique and vulnerable eco-landscapes in this region. Anthropogenic activities have been mainly restricted to areas along the river meandered between the mountains and the desert ranges. The lower Tarim River and the Lop Nur (e.g., once the largest lake in China) dried up in 1970 and 1972, respectively, due to anthropogenic stream flow interruption. Large-scale desertification had occurred in these areas [15].

There are unique geographical, ecological, climatological and social-economic features which make the Tarim River Basin sensitive to the terrestrial ecosystem dynamics and distribution shift as well as vulnerable to climate change and anthropogenic disturbance. The Tarim Basin is: 1) an arid or semi-arid climate environment, shaded by the surrounding high mountains, 2) an isolated hydrological unit of the endorheic basin, 3) diversity in landscape, desert, wetlands, alpine meadow, mountains, 4) unstable ecosystem, and 5) rapid economic development in many sub-basins. These factors had collectively caused environmental 
degradation including desertification, riparian vegetation and grassland degradation, and the loss of biodiversity. With these unique features, the vegetation dynamics and LUCC over the past decades have thus drawn a lot of international attention. The Chinese government has initiated a large ecological restoration project since 2000, which has shown some of the success in restoring the river's flow and vegetation cover along the corridor of the river.

\section{MATERIALS AND METHODS}

The VEGETATION instruments on board SPOT4 launched in April 1998 and SPOT5 launched in May 2002 provide measurements of the land surface reflectance in the visible and infrared domains. These sensors offer daily global coverage with a spatial resolution of about $1 \mathrm{~km}^{2}$. Reflectance measurements are performed within four spectral window: Blue (B0: $0.43-0.47 \mu \mathrm{m})$, Red (B2: 0.61-0.68 $\mu \mathrm{m}$ ), Near Infrared (NIR: 0.78-0.89 $\mu \mathrm{m}$ ), and Medium Infrared (MIR: $1.58-1.75 \mu \mathrm{m}$ ) with a high spectral (absolute calibration accuracy of about $5 \%$ ) and geometric accuracy (less than 0.3 pixel) [42]. Changes in vegetation cover are inferred using the well-known NDVI.

The measured NDVI signal may be influenced by clouds and other unfavorable conditions (e.g., large view angles, atmospheric haze, and etc.). Taking the maximum NDVI value over a period of time may automatically screen out the abnormal observations [41]. This can be anticipated when using the VGT-S10 products that are compiled by merging segments (data strips) acquired in a ten-day period (e.g., the ten-day synthesis). During processing, all the segments of this 10-day period are compared with each other pixel by pixel to pick up the 'best' ground reflectance values based on a Maximum Value Composite (MVC) algorithm [41]. The advantage of the ten-day synthesis data is that the highest signal data within the tenday period is employed as a pixel value for the ten-day synthesis data; therefore, the cloud cover influences are favorably reduced. There are three S10 (ten-day composite) products (i.e., S01, S11, and S21) in each month [42], and they represent the first ten-day, the middle tenday, and the last ten-day of a month, respectively.

In this study, the SPOT-Vegetation S10 NDVI data from 1998 to 2007 acquired over the study area were used. We selected the summer months between April and October as the growing season of vegetation, which is the period when vegetation is active. Then, the monthly NDVI values were generated from April to October using the MVC algorithm based on the S10 NDVI data. The monthly NDVI data were imported to the real value range using the equation " $0.004 * \mathrm{DN}-0.1$ "” where the Digital Number (DN) is the value stored for a pixel of an image [40,42], and were projected into Albers conformal conic projection using ArcGIS by the authors. One useful way to identify vegetation dynamics in NDVI images is to look at "signature" or "time-series plots" of the NDVI levels of the pixel in the image. Vegetation activity follows the trend of seasonality. Namely, as vegetation grows, NDVI increases. The cyclic increase and decrease of NDVI over time in a given area is the character of vegetation growth cycle and is taken as an indicator of the presence or the absence of vegetation $[43,44]$.

In statistics, $\mathrm{CoV}$ is simply a value calculated from the average, or mean $(\mu)$ and the standard deviation $(\sigma)$ of the NDVI time series in each pixel $[27,47,48]$, whose formula is as follows:

$$
\operatorname{CoV}=\frac{\sigma}{\mu}=\frac{\sqrt{\frac{1}{n} \sum_{i=1}^{n}\left(X_{i}-\overline{X_{i}}\right)^{2}}}{\frac{1}{n} \sum_{i=1}^{n} X_{i}}
$$


where $X_{i}$ is the $\mathrm{i}^{\text {th }}$ sample (value) of a variable (pixel), and $\mathrm{n}$ is the number of samples.

We employed the seasonally accumulated NDVI value, denoted as $\sum$ NDVI hereafter, in each pixel for analysis. $\sum$ NDVI is therefore defined as the sum of monthly NDVI during the growing season, which is highly related to the net primary production (NPP) [45, 46]. The statistics of $\mathrm{CoV}$ has been widely used to determine the spatial difference of temporal variability of vegetation activity in different arid and semi-arid regions of the world [27]. Changes in the value of the pixel-level CoV over time can be interpreted as a measure of vegetation dynamics over that time period. In other words, a higher NDVI CoV for a given pixel represents a greater change.

To finally pin down the vegetation dynamics, the intra-annual CoV derived from monthly NDVI values and the inter-annual $\mathrm{CoV}$ derived from $\sum$ NDVI values were respectively calculated. The inter-annual $\mathrm{CoV}$ may reflect the overall change of the vegetation in the given period of time, while the intra-annual $\mathrm{CoV}$ can be used as a measure of vegetation growth cycles in an area within a year. To establish a means for detecting and quantifying the continuous changes of intra-annual $\mathrm{CoV}$ in each pixel, a linear regression analysis between intra-annual $\mathrm{CoV}$ time series (i.e., Y values in equation (2)) and time from 1998-2007 (i.e., $X$ values in equation (2)) was used. The practice of such a linear regression enables us to reveal the long-term trend of $\mathrm{CoV}$, which is intimately related to multitemporal vegetation dynamics. Mathematically, it is provided by the equation of the straight-line best fitting the set of intraannual $\mathrm{CoV}$ values for each pixel.

$$
Y=\alpha X+\beta
$$

In the above equation, the slope " $\alpha$ " may act as a "sustainability indicator" for the change detection of land cover dynamics in the study area [49]. If the slope of this regression exhibits a negative sign showing a statistically decreasing trend over time, it may be concluded that the temporal variability of NDVI was declining due to LUCC; conversely, if the slope of this regression line shows a positive sign indicating a statistically increasing trend, it may be concluded that the temporal variability of NDVI was increasing due to changes in primary production during green-up in the study area.

\section{RESULTS}

\subsection{Spatial patterns of mean $\sum$ NDVI and inter-annual CoV}

The spatial patterns of vegetation cover can reflect the spatial characteristics in relation to climate and topography, and reveal the differences in water resources utilization in human society simultaneously. Fig. 2 presents the mean KNDVI between 1998 and 2007 in the Tarim River Basin, which shows obvious difference in space. The values range from 0 to 5 . The mean $\sum$ NDVI values produced above help provide a better understanding of the overall spatial characteristics of NPP on one hand and explore the possible anthropogenic perturbations on the other hand in the basin. The lowest values (less than 0.5) are recorded in the basin center (the Taklamakan Desert) and high mountainous region at altitudes higher than $3,000 \mathrm{~m}$, where the precipitation is infrequent but the PET is intense. Vegetation cover is scarce in these regions and this type of vegetation cover accounts for a significant proportion of vegetation cover in the Tarim River Basin. The relatively higher values of the mean $\sum$ NDVI ranging from 0.5 to 2.5 accounted for the greater natural vegetation cover which mostly occurs along the mountainside at altitudes lower than $3,000 \mathrm{~m}$. The land in the plains area where the cultivated vegetation has developed along the river corridor after water flow out of mountains was cut off often have the highest values of the mean $\sum$ NDVI (e.g., between 1 and 5). As a special case, high values of the mean $\sum$ NDVI also appeared in the alpine 
meadow regions in Lake Bosten valley located in the northeast Tarim River Basin where the second largest grassland in China is located at altitude about $2,500 \mathrm{~m}$.

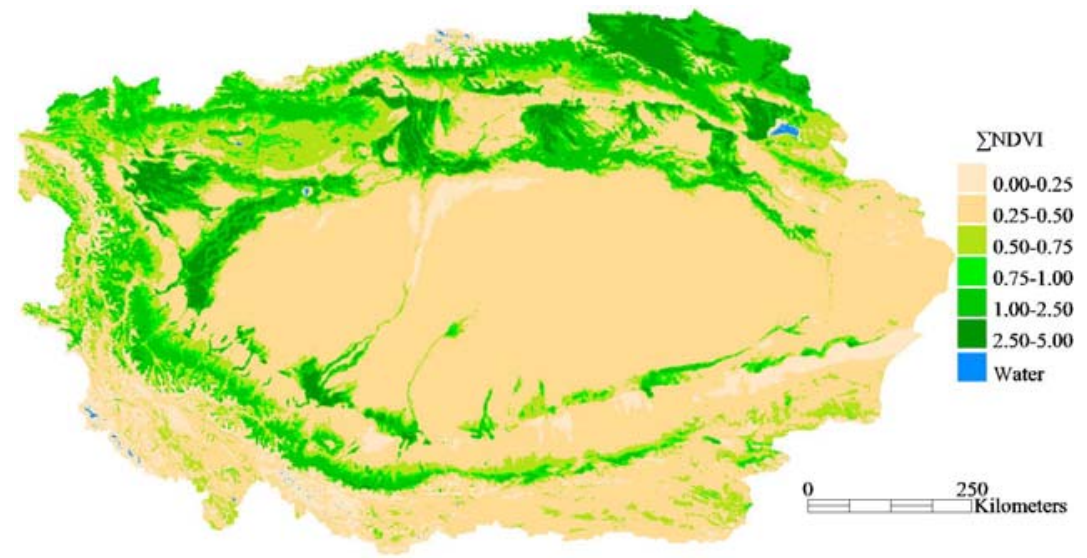

Fig. 2. Spatial distribution of mean $\sum$ NDVI

Fig. 3 presents the inter-annual $\mathrm{CoV}$ values, which reflects the salient spatial patterns of overall vegetation dynamics between 1998 and 2007. The inter-annual CoV exhibits obvious difference in distribution when compared with the counterpart of mean $\sum$ NDVI in Fig. 2 . The areas with the lowest inter-annual $\mathrm{CoV}$ values (i.e., less than 0.15) scattered around the central Taklamakan desert and most of the mountainous regions of Tianshan and eastern Kunlun indicating the smallest temporal changes in vegetation over the years. Yet the interannual $\mathrm{CoV}$ values increased along the north and southwest edges of the desert (i.e., 0.150.25). The areas with the highest inter-annual $\mathrm{CoV}$ values are located in southwestward slopes of Kunlun and Pamir, and some areas in central Tianshan, with values higher than 0.85 . The distribution of inter-annual CoV values versus $\sum$ NDVI is presented in Fig. 4. In general, the areas with significant changes are pixels with mean $\sum$ NDVI less than 0.4 in association with the inter-annual $\mathrm{CoV}$ values between 0.25 and 1.5. Normally, these regions are less related to cultivated land use. When the mean $\sum$ NDVI values are higher than 1.3, the variation of vegetation cover over years becomes smaller. For most of the study areas where exhibit minimal change in mean $\sum$ NDVI, the inter-annual CoV values range between 0.05 and 0.25.

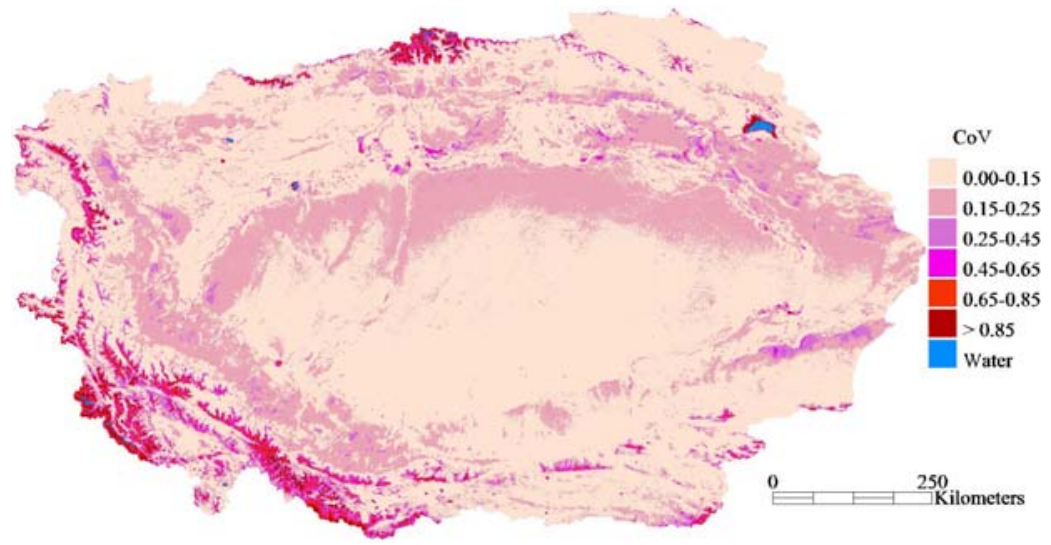

Fig. 3. The spatial distribution of inter-annual $\mathrm{CoV}$ 


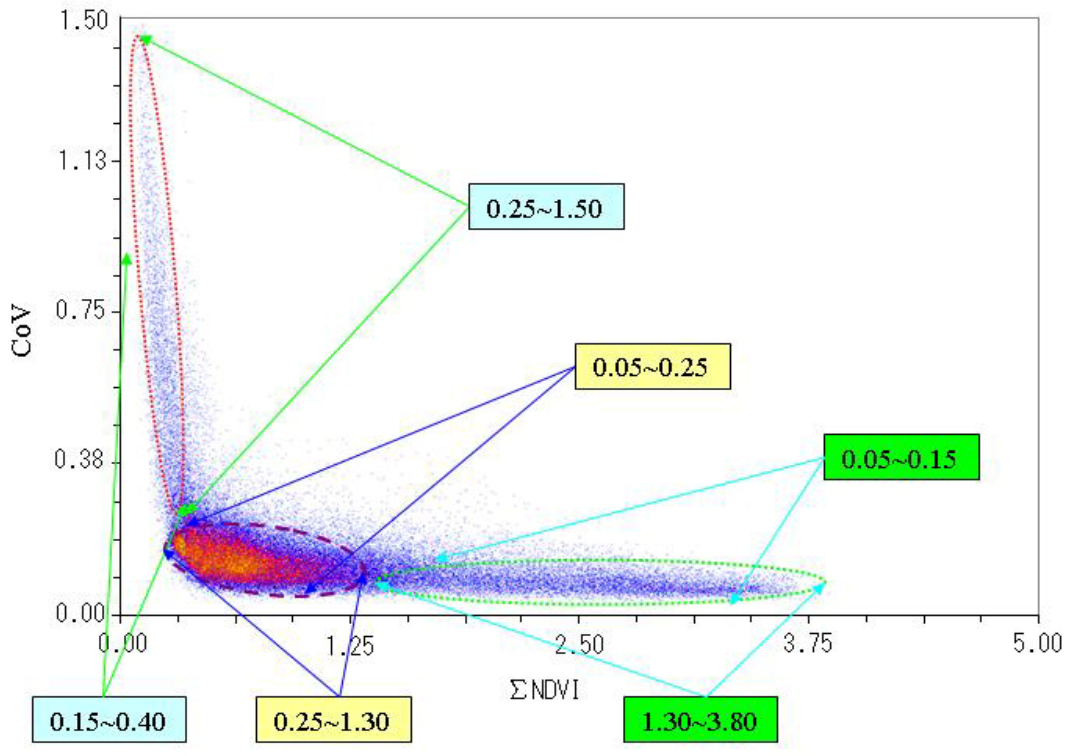

Fig. 4. The distribution of the inter-annual CoV values versus the mean $\sum$ NDVI

\subsection{Temporal variability of mean $\sum$ NDVI}

The time series of the mean $\sum$ NDVI values of the whole study region may reflect the overall vegetation dynamics over time, which can be linked with changes in LULC. In arid region, land degradation often results in a declining NDVI CoV; thus, a decline in temporal variability of NDVI can serve as an indicator of land degradation. Fig. 5 shows the mean of intra-annual $\sum$ NDVI associated with all pixels of the study region during the period of 19982007. From 1998 to 2001 , the value dropped sharply from 0.68 to 0.56 , then increased rapidly up to 0.71 in 2003; between 2003 and 2005, the value kept stable about 0.71 ; and since then, it decreased again back to 0.65 in 2007. Overall, these values fluctuated between 0.56 and 0.72 . To examine the true driving force of such natural vegetation dynamics, TRMM/PR data were introduced as coincident indicator for assessment. Fig. 6 shows the temporal variability of mean annual precipitation over the Tarim Basin from 1998 to 2007. It also reveals that the extreme or peak values of intra-annual $\sum$ NDVI are consistent with those in precipitation, and the sharp drop of intra-annual $\sum$ NDVI during between 1999 and 2001 is most likely due to the presence of continuous drought over the three years in the same time period.

By comparing Fig. 5 and Fig.6, general consistency may be confirmed in terms of the characteristics of temporal variability between the mean $\sum$ NDVI and the mean precipitation over the Tarim River Basin from 1998 to 2007, both of which recorded the lowest and highest values in 2001 and 2005, respectively. An inconsistency observed in 2004, however, which might be due to the resilience of the vegetated land as long as the drought impact is tentative. Another possibility is that the irrigated vegetation always shows relatively stable land cover no matter how much precipitation decreased, only if the runoff from mountains is not dropped greatly. Given that the runoff comes not only from precipitation but also from melting glaciers of the headstreams of Tarim River, the irrigation water may still be sufficient even though precipitation turn out smaller. On the contrary, a sharp decline of natural vegetation cover in the continuous drought events between 1999 and 2001 manifests the vulnerability of the ecosystem in the study region. 


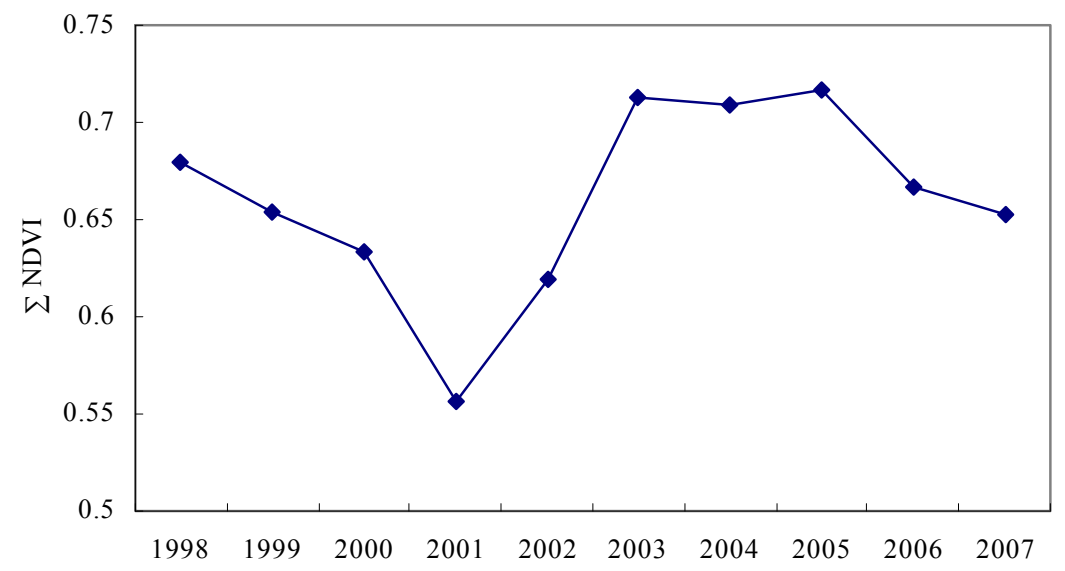

Fig. 5. The temporal variability of the mean $\sum$ NDVI values in the whole study region from

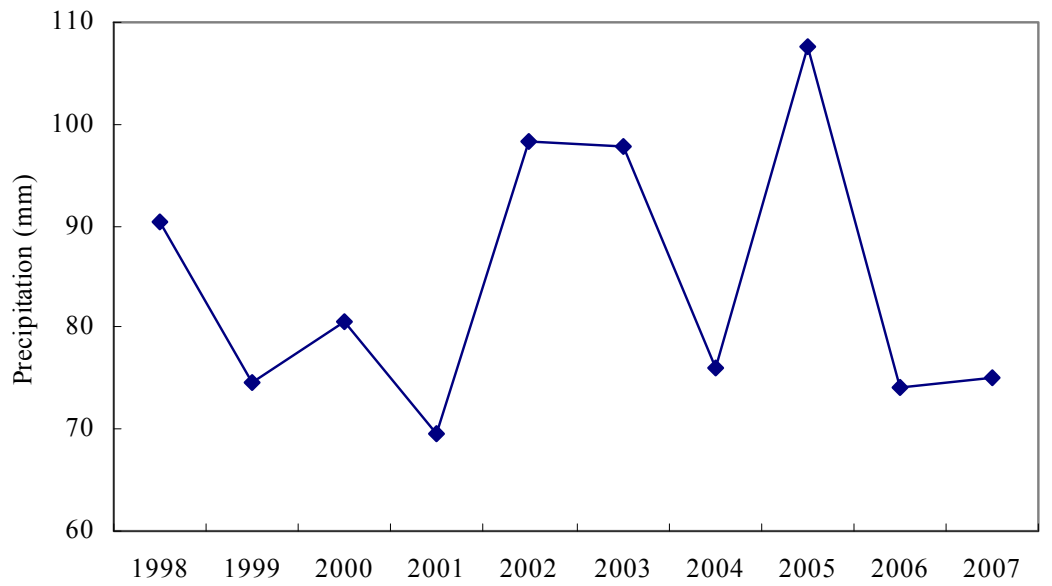

Fig. 6. Temporal variability of mean annual precipitation over the Tarim Basin 1998 to 2007

\subsection{Vegetation dynamics in growing seasons}

The slope factor of the linear regression associated with the intra-annual CoV of NDVI for the study period from 1998 to 2007 is shown in Fig. 7. The figure color scheme is that white and green represent regions where the regression slope is positive and red, regions where the regression slope is negative. In other words, the figure represents those areas with increasing vegetation cover (e.g., green) and areas with declining vegetation cover (e.g., red). Fig. 7 also shows that there has been systematic vegetation cover at some southward slopes of the Kunlun Mountains and the southwest Tarim River Basin. Another notable region with improvements of vegetation cover is central Tianshan Mountain. These regions have elevation higher than 3,000 $\mathrm{m}$ and have very lower values of the mean $\sum$ NDVI (see Fig. 2). However, in the northern Taklamakan Desert, some of the southern edge of the desert and some mountainous areas in Tianshan show a decreasing trend. It is worth noting that a number of emerged green spots, whcih were close to irritated land, indicate new farmland being cultivated very recently or rotated by possible changes in crop types. At the same time, the vegetation cover in the lower reaches of the Tarim River exhibits clear evidence of degradation. 


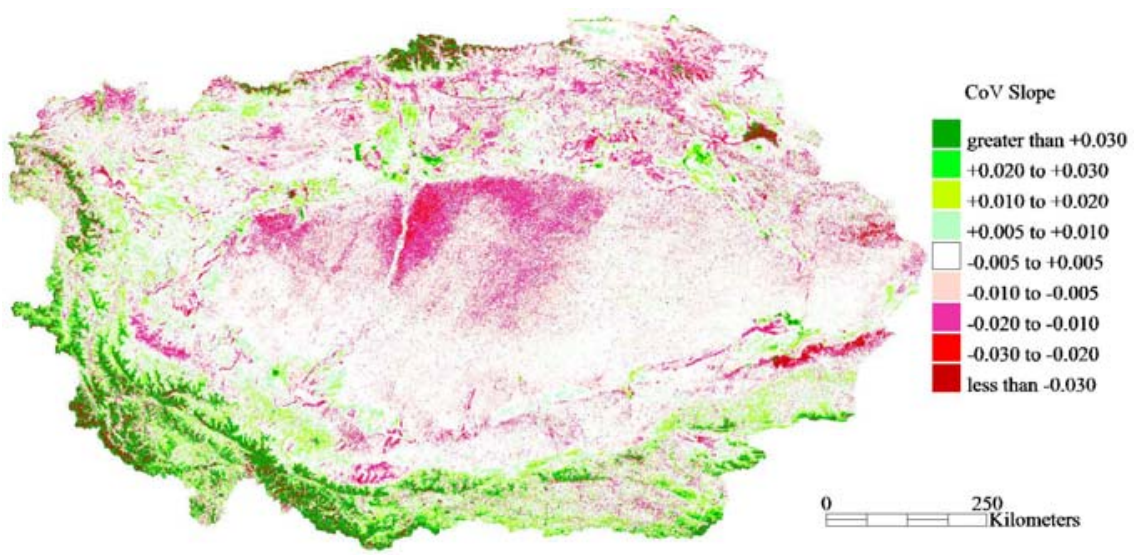

Fig.7. The slope map of the intra-annual CoV of NDVI in the Tarim Basin

When compared with Fig. 3, the distribution of the intra-annual CoV slope is, to some extent, similar to that of the inter-annual $\mathrm{CoV}$, indicating the gross vegetation changes during the study period. Therefore, the major changes in vegetation cover can be summarized as follows: 1) there was a systematically increasing trend in natural vegetation in the high mountainous region southward; and 2) there was no increasing trend of vegetation in most of the plains region, but some exceptions appeared in the downstream of main tributaries. In an attempt to explore the reasons causing such changes, the next section discussed and summarized some of the insights from the perspectives of climate change and anthropogenic perturbations.

\section{DISCUSSION}

\subsection{Climate change}

Previous studies showed that recent climate conditions in the Central Asia region in China had favored more precipitation or snowmelts [12]. As a result of global warming and an enhanced water cycle, the climate change impacts have been notably salient in Xinjiang since 1987, which can be characterized by a shift from a warm-dry to a warm-wet annual pattern $[11,38]$. In this region, the temperature has risen by nearly $1{ }^{\circ} \mathrm{C}$ over the past 50 years [48]. The melting glaciers in the 1990s resulted in a more than $5.5 \%$ increase in river runoff in the Tarim River Basin $[12,50]$. As a consequence, the vegetation cover has improved in some parts of the basin and the total number of days with sand-dust storms has reduced [50].

In parallel with the spatio-temporal analysis of vegetation dynamics, the precipitation trend can be illustrated by the same type of slope factor with respect to intra-annual precipitation during the growing seasons from 1998 to 2007. By the same token, a linear regression analysis between intra-annual precipitation time series (i.e., $\mathrm{Y}$ values in equation (2)) and time from 1998-2007 (i.e., $X$ values in equation (2)) was used. The practice of such a linear regression enables us to reveal the long-term trend of precipitation, which is intimately related to multitemporal vegetation dynamics. Mathematically, it is provided by the equation of the straight-line best fitting the set of intra-annual precipitation values for each pixel.

$$
Y=\alpha^{\prime} X+\beta^{\prime}
$$

Such a slope factor, $\alpha^{\prime}$, may also be used as a sustainability indicator in concert with the slope of intra-annual CoV of NDVI in ecosystem assessment. Fig. 8 shows an increasing trend in the southern edge of the Tarim River Basin and Central Tianshan Mountains. Apparently, the 
northern Tarim Basin and major part of the Tianshan Mountains, particularly the northeast and northwest areas, were undergoing a declining trend from 1998 to 2007. Comparisons between Fig. 7 and Fig. 8 indicate that remarkable consistency exists between vegetation dynamics and precipitation changes in certain regions over the past 10 years. Yet some regions show obviously different or reverse trends, e.g., the high mountainous areas on the fringe of the southwest basin. There is an inconsistency in increasing precipitation and declining slope of the intra-annual CoV of NDVI in the Central Taklimakan Desert. This does not mean the positive relationship between vegetation dynamics and precipitation observed over the high mountainous areas on the fringe of the southwest basin is simply fortuitous. The reason for having such an outcome is highly associated with the interactions between land surface temperature (LST) and evapotranspiration (ET) in the sense that no residual precipitation can be left over for vegetation cover, if any, after the water consumption through actual evapotranspiration (AET) in the Central Taklimakan Desert.

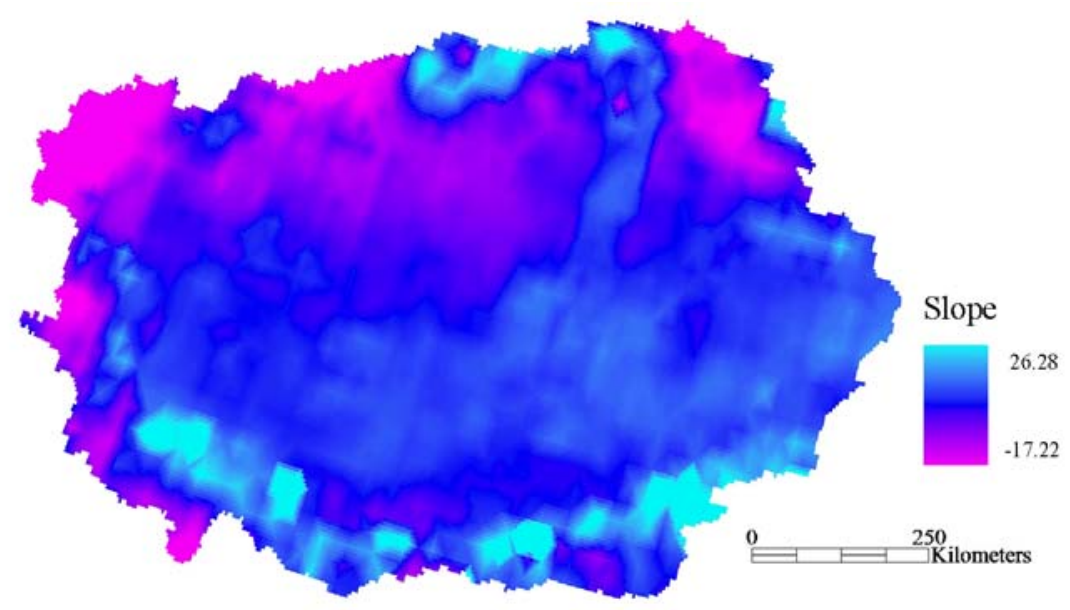

Fig. 8. The distribution of Slope factor of intra-annual precipitation in the Tarim River Basin

Through the comparison of spatial trends between precipitation and vegetation cover in the Tarim River Basin, it may be concluded that obvious relationship exists between precipitation patterns and vegetation dynamics in the context of global climate changes. For certain areas, there were remarkable consistencies between the increase of precipitation and the improvement of vegetation cover. However, discrepancies also existed in some areas where increased vegetation cover came with declined precipitation. It is well known that climate warming leads to an accelerated ablation and retreat of high mountain glaciers in most parts of the world, and to a runoff increase in the short to middle term [50-52]. These studies indicate that the improvement of vegetation cover may also be triggered by other mechanisms, i.e. rise in temperature, permafrost degradation, glacier and snow melt etc.

In arid regions, the distribution of vegetation is certainly tied to the groundwater and soil moisture. From the ecological point of view, the pools of soil moisture are fundamental ecosystem resources providing the transpirable water for plants. In drylands particularly, soil moisture is one of the major controls on the structure, function, and diversity in ecosystems [53]. In the vast plain regions of the Tarim Basin, soil moisture is the most important factors which restrict vegetation growth. The dynamics of soil moisture are vital to maintaining biodiversity and better understanding of the eco-hydrological process.

Previously, estimates of soil moisture over large area have been limited by a lack of observational data and technology. There is currently a gap in our ability to use limited point 
measurement of soil moisture data for hydrological, ecohydrological, and biogeochemical studies at a basin scale. But the technology of measuring soil moisture content has been progressively improved over the years [53-56]. Wang et al. used the Advanced Microwave Scanning Radiometer (AMSR-E) dataset to conduct the surface soil moisture for an arid area, and the patterns of mean annual surface soil moisture were successfully estimated [55]. As the most common imaging active microwave configuration, SAR represents the best approach for obtaining spatially distributed surface soil moisture with a much better resolution. Associated with hydrological models, it is expected to obtain distributed soil moisture profiles [56]. There are also other promising avenues of instrumentation research in this field (e.g., gravity measurements, acoustic waves). There is obvious potential of using soil moisture data collected by SAR to benefit the ecosystem assessment applications if larger temporal resolution is not a concern.

\subsection{Anthropogenic perturbations}

In the hydrological cycle, some processes are not under human control, like precipitation, but others, like groundwater recharge, can be modified by differing LULC. As a consequence, human beings may influence or even alter the hydrological cycle by several ways. Examples in the Tarim River Basin include dam building, change of river course, farmland reclamation, and agricultural irrigation. Although river runoff increased due to climate change, the terrestrial vegetation (or ecosystem) experienced quite a different process at different parts of the basin due to varying anthropogenic activities. Sometimes, it causes conflict between human needs and environmental goals. To explore the sustainable development at the great western region of China, there are two examples with sharp contrast, as a result of rapidly socioeconomic development in the Tarim River Basin, which may deserve further investigation as follows.

\section{1) Large patches of irrigated farmland}

In the plain areas, no runoff was actually generated from precipitation due to insufficient amount of rainfall which could not even offset the strong evaporation. Nevertheless, with the fertile soil and favorable solar insolation, the plain areas turn out to be the ideal regions for artificial irrigation as long as the irrigation water can be diverted from the headstreams. As a result, large patches of farmland had been cultivated on the fringes of the desert that receive the runoff right after it runs out of mountains. A salient example is on the northern fringe of the basin fed by the Aksu River (see Fig. 1) before it runs into the mainstream of the Tarim River. Fig. 9 presents a typical spatial structure of irrigated farmland which was spanned from the source of water in a uniquely radial manner at different scales on the northern fringe of the basin. Based on this feature, Zhou et al. had developed a methodology to quantify spatial patterns of LUCC using landscape metrics, which provided an approach distinguishing human-induced change with the aid of multi-scale and multi-temporal remotely sensed data [57-58]. Such a case study confirmed that spatio-temporal patterns of environmental changes can be largely represented by changes in LULC in the middle reaches of the Tarim River from 1973 to 2000 .

In this basin, the recorded population has nearly tripled from 1.77 million in 1958 to 4.55 million in 2003 [59]. The agricultural development was preceded by a rapid population growth. Ninety seven percent of the population had inhabited tails of the headstream as indicated in the left picture of Fig. 9. Only $2.14 \%$ and $1 \%$ were resided in middle and lower reaches, respectively [59]. The figure is in accordance with the research results from Zhou et al. [58]. Although the human impacts altering water resources and land surface have increased dramatically in recent years, it is still not a dominant force in the middle reaches of the Tarim River. Fig. 10 summarizes the change in cultivated land in the Tarim Basin from 1958 to 2003 
[59]. It shows that the cultivated land expanded remarkably in the head stream regions. Farmland increased by about $30 \times 10^{4}$ hectares at tails of headstreams, and the area was doubled in the upper and middle river corridors while there was almost no change of population in the lower reaches at the same time. Combining the temperature, precipitation and hydrological data from three headstreams of the Tarim River, the plausible association between climate change and the variability of water resources in the Tarim River Basin in recent years was investigated by Chen et al. [60]. They also concluded that climate change had resulted in the increase of the streamflow at the headwater of the Tarim River, but the anthropogenic activities such as over-depletion of the surface water resulted in the decrease of the streamflow at the lower reaches of the Tarim River.
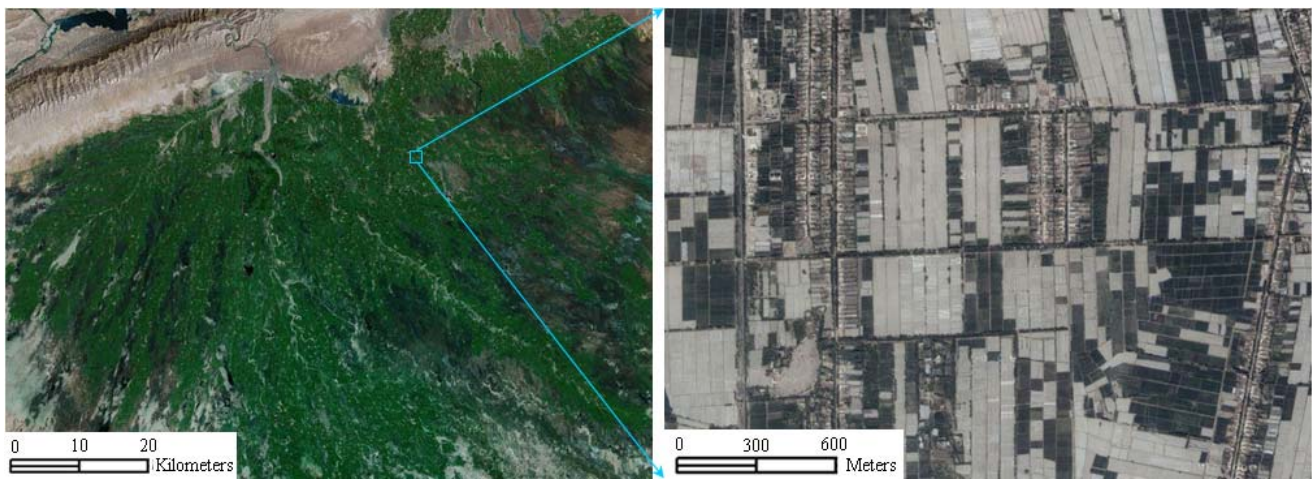

Fig. 9. Spatial structure of farmland between desert and mountain at different scales

In short, the eco-hydrological situation has actually improved in the upstream mountainous areas as a result of climate change, but there has not been a corresponding improvement in the downstream water volume. This is due to the fact that much of the runoff from headstreams was intercepted for agricultural irrigation. The total discharges of four major headstreams are larger than the long-term average of river discharge by $21.0 \%$ and $17.4 \%$ in 2005 and 2006, respectively [61-62]. Yet the natural increase in runoff did not offset the increasing water demand needed for more irrigated farmland. As a consequence, the main Tarim River did not receive an increase of the discharge resulting in very little benefit to the new settlements in the lower reaches of the Tarim River. If the discharge of headstreams drops to average level or even lower, residual water flow discharging into the mainstream could even deteriorate more, resulting in further deterioration in the ecosystem restoration in the lower reaches of the Tarim River. It may be concluded that agricultural sector which accounts for approximately $90 \%$ of the total water consumption is obviously a major driving force in adaptive water resources management. Aligned with this point, the land reclamation activities converting farmland back to natural grassland in the upper reaches should be followed through for the purpose of sustainable development. 


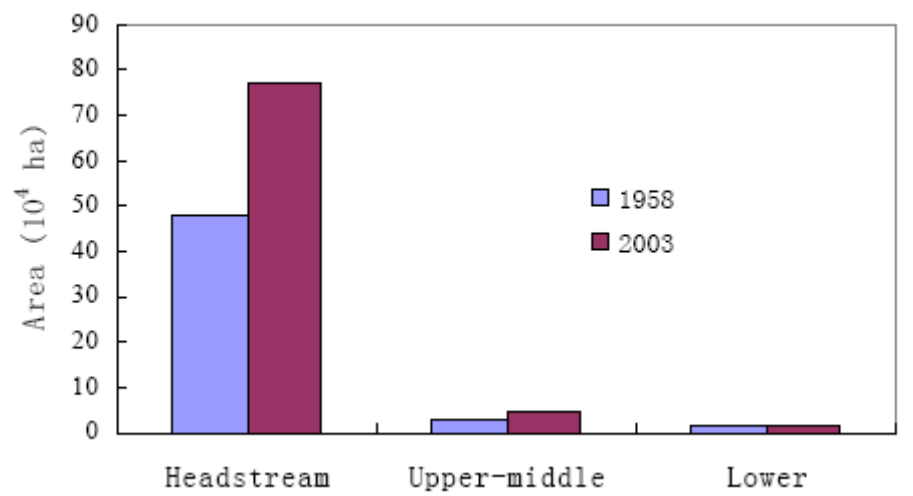

Fig. 10. Change of cultivated land in Tarim Basin from 1958 to 2003 [59]

\section{2) Degradation of ecosystem in the lower reaches of the Tarim River}

Contrasting with the thriving agriculture in the upper reaches of the Tarim Basin, the runoff interruption in the lower reaches of the Tarim River is significant. The dried rivers and terminal lakes resulted in an extensive desertification in the lower reaches of the Tarim River. Because the agricultural irrigation consumed major part of source water in the upper reaches before it discharged into the mainstream of the Tarim River, it ended up drying out $300 \mathrm{~km}$ of the lower Tarim River in 1970s. Two big terminal lakes were erased from the land surface as a result of this impact. Since then large-scale desertification has occurred continuously in the lower reaches of the Tarim River. Table 1 lists the situation of desertification of the lower Tarim River at Alagan area [59]. This is evidence that heavy degree desertification appears to be increasing over time.

Table 1. Evolution of desertification in the lower Tarim River (Alagan) $\left(\mathrm{km}^{2}, \%\right)$.

\begin{tabular}{|c|c|c|c|c|c|c|c|c|c|c|}
\hline \multirow{2}{*}{ year } & \multicolumn{2}{|c|}{ Total } & \multicolumn{2}{c|}{ Extreme } & \multicolumn{2}{c|}{ Heavy } & \multicolumn{2}{c|}{ Moderate } & \multicolumn{2}{c|}{ Light } \\
\cline { 2 - 11 } & area & portion & area & portion & area & portion & area & portion & area & portion \\
\hline 1959 & 1371.2 & 86.9 & 476.6 & 30.2 & 95.8 & 6.10 & 393.4 & 24.9 & 405.9 & 25.7 \\
\hline 1983 & 1460.2 & 92.6 & 497.6 & 31.6 & 96.6 & 6.1 & 454.9 & 28.9 & 411.1 & 26.1 \\
\hline 1992 & 1487.3 & 94.3 & 532.2 & 33.8 & 145.0 & 9.2 & 438.0 & 27.8 & 372.0 & 23.6 \\
\hline 1996 & 1494.3 & 94.8 & 555.4 & 35.2 & 184.0 & 11.7 & 437.9 & 27.8 & 316.9 & 20.1 \\
\hline
\end{tabular}

To reverse this ecosystem deterioration, the Chinese government invested more than 10 billion Yuan (i.e., The average Chinese Yuan conversion rate over the last 12 months was 6.82 yuan /US dollar in 2010.) to initiate an ecological restoration project since 2000. Although the restoration project had minimum level of success in the last 10 years, it is still far from a level providing an optimistic outlook in the near future based on our field investigation, as shown in Fig. 9. Shown here are a dried reservoir (Daxihai) (left picture) and the desertified riverbed with withered Populus euphratica (right picture) in the lower Tarim River at Alagan. This demonstrates an acute need for advanced conservation actions. In general, there are no potential surface water resources left for exploitation in the Tarim Basin, but there is considerable potential for water savings through the application of conventional techniques, such as adoption of drip and sprinkler irrigation, using plastic row covers, etc. 
Ultimately, the restoration efforts have to be enhanced relative to the notably increased farmland in the upper Tarim River (see Fig. 6).
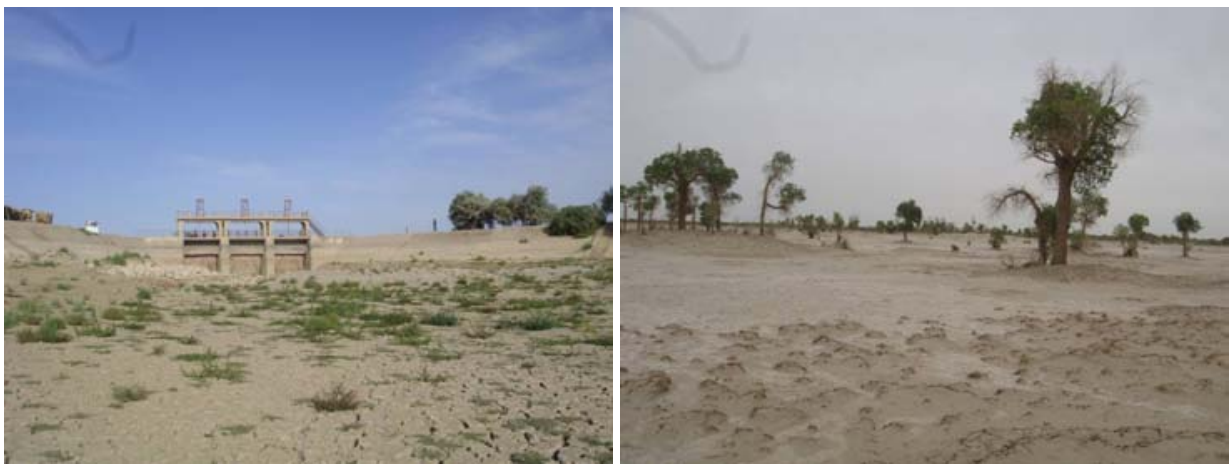

Fig. 9. Snapshot of the dried up reservoir (left), the desertification riverbed and the withered Populus euphratica (right) in the lower Tarim River in June 2009.

\section{CONCLUSIONS}

In arid regions, sustainable development requires a better understanding of the ecohydrological process and water management strategies from both social contexts and ecological perspectives [63]. Conflict management can be a significant means in dealing with environmental degradation. To achieve this goal, sensing and monitoring the dynamics of vegetation is deemed very important for a better understanding in regard to infrastructure, society, and environments, establishing links between policy decisions, regulatory actions, and subsequent land-use management. In this study, the SPOT-VGT NDVI continuous time series data provide us with an opportunity to monitor vegetation cover conditions over large geographic regions at a decadal time scale. Changes induced by coupled effects of climate change impacts and anthropogenic perturbations can be detected simultaneously at the required temporal and spatial resolutions. Should the soil moisture information may be concluded in parallel with the measurements of vegetation dynamics and precipitation, more aspects in ecosystem assessment may be explored.

Nevertheless, research findings in this study clearly indicate that there was a systematic trend of increasing natural vegetation cover in the high mountainous region of the Tarim Basin, which was most likely associated with climate change in South and Central Asia. As a consequence, in some high mountainous areas, precipitation may not be the major restriction on vegetation growth. More sporadic vegetation growth may be related to other mechanisms driven by the rise in temperature, permafrost degradation, glacier and snow melt, etc. Whereas the vegetation cover changes in fluvial plains reflect the ever increasing anthropogenic perturbations via agricultural irrigation, the natural vegetation cover was undergoing a degradation process regardless of the ever enhanced hydrological process in the upper reaches of the Tarim River due to more precipitation To deal with this impact, China has been active in fighting environmental degradation while implementing the "Great Western Development Strategy" at the same time. Some movement could be economically sounds yet environmentally uncertain. In many areas, such as the Tarim River Basin, as "environmental damage" is apparent, more ecosystem assessment and restoration actions will be required to facilitate the sustainable development in the future. 


\section{Acknowledgments}

This work was financially supported by the Natural Science Foundation of China (NSFC No. 40371022, 40701025), the German Academic Exchange Service (DAAD) and Robert Bosch Foundation on Sustainable Partners (No.32.5.8003.0063.0/MA01). The authors would also like to thank Environmental and Ecological Science Data Center for West China for their provision of SPOT-VGT NDVI data. Useful comments from anonymous referees are gratefully acknowledged.

\section{References}

[1] IPCC, Fourth Assessment Report, Climate Change 2007: Impacts, Adaptation and Vulnerability, "http://www.ipcc.ch".

[2] P. M. Vitousek, "Beyond Global Warming - Ecology and Global Change," Ecology. 75, 1861-1876, (1994) [doi:10.2307/1941591].

[3] IGBP, "http://www.igbp.net/".

[4] M. Edwards and A. J. Richardson, "Impact of climate change on marine pelagic phenology and trophic mismatch," Nature. 430, 881-884, (2004) [doi:10.1038/nature02808].

[5] L. Hughes, "Biological consequences of global warming: is the signal already apparent?" Trends in Ecology \& Evolution. 15, 56-61, (2000) [doi:10.1016/S01695347(99)01764-4].

[6] C. Parmesan and G. Yohe, "A globally coherent fingerprint of climate change impacts across natural systems," Nature. 421, 37-42, (2003) [doi:10.1038/nature01286].

[7] D. S. Schimel, "Drylands in the Earth System," Science. 327, 418-419, (2010) [doi: 10.1126/science.1184946].

[8] E. Rotenberg and D. Yakir, "Contribution of semi-arid forests to the climate system," Science. 327, 451-454, (2010) [doi:10.1126/science.1179998].

[9] M. M. Verstraete and S. A. Schwartz, "Desertification and global change," Plant Ecology. 91, 3-13, (1991) [doi:10.1007/BF00036043].

[10] N. F. Hadley and S. R. Szarek, "Productivity of desert ecosystems," Bioscience. 31, 747-753, (1981) [doi:10.2307/1308782].

[11] Y. Shi, Y. Shen, E. Kang, D. Li, Y. Ding, G. Zhang, and R. Hu, "Recent and future climate change in Northwest China," Climatic Change. 80, 379-393, (2007) [doi:10.1007/s10584-006-9121-7].

[12] T. Yao, Y. Wang, S. Liu, J. Pu, Y. Shen, and A. Lu, "Recent glacial retreat in High Asia in China and its impact on water resource in Northwest China," Science in China Series D: Earth Sciences. 47, 1065-1075, (2004) [doi:10.1360/03yd0256].

[13] J. Y. Lin, F. Cai, and Z. Li, The China miracle: development strategy and economic reform The Chinese University Press, (2003).

[14] L. Ding and A. W. N. William, China's west region development: domestic strategies and global implications world Scientific Publishing Co. Pte. Ltd, (2004).

[15] Q. Feng, W. Liu, J. H. Si, Y. H. Su, Y. W. Zhang, Z. Q. Cang, and H. Y. Xi, "Environmental effects of water resource development and use in the Tarim River basin of northwestern China," Environ Geol. 48, 202-210, (2005) [doi:10.1007/s00254-005-1288-0].

[16]R. W. G. Caldow and P. A. Racey, "Large-scale processes in ecology and hydrology," J Appl Ecol. 37, 6-12, (2000) [doi:10.1046/j.1365-2664.2000.00559.x].

[17] S. Ringrose and W. Matheson, "A landsat analysis of range conditions in the Botswana Kalahari drought," Int J Remote Sens. 12, 1023-1051, (1991) [doi: $10.1080 / 01431169108929708]$. 
[18]P. Serra, X. Pons, and D. Sauri, "Post-classification change detection with data from different sensors: some accuracy considerations," Int J Remote Sens. 24, 3311 - 3340, (2003) [doi:10.1080/714110283].

[19] A. Bannari, D. Morin, F. Bonn, and A. R. Huete, "A review of vegetation indices," Remote Sensing Reviews. 13, 95 - 120, (1995) [doi:10.1080/02757259509532298].

[20] J. Weier and D. Herring, "Measuring vegetation (NDVI \& EVI). Earth Observatory, NASA. http://earthobservatory.nasa.gov/Library/MeasuringVegetation/printall.php," (2006).

[21] R. D. Jackson, "Spectral indices in N-Space," Remote Sens Environ. 13, 409-421, (1983) [doi:10.1016/0034-4257(83)90010-X].

[22] J. W. Rouse, J R., R. H. Haas, J. A. Schell, and D. W. Deering, "Monitoring vegetation systems in the Great Plains with ERTS " NASA. Goddard Space Flight Center 3d ERTS-1 Symp. 1, 309-317, (1973).

[23] J. L. Weiss, D. S. Gutzler, J. E. A. Coonrod, and C. N. Dahm, "Long-term vegetation monitoring with NDVI in a diverse semi-arid setting, central New Mexico, USA," J Arid Environ. 58, 249-272, (2004) [doi:10.1016/j.jaridenv.2003.07.001].

[24] O. Diallo, A. Diouf, N. P. Hanan, A. Ndiaye, and Y. Prevost, "Avhrr monitoring of savanna primary production in Senegal, West Africa - 1987-1988," Int J Remote Sens. 12, 1259-1279, (1991) [doi:10.1080/01431169108929725].

[25] S. E. Nicholson, M. L. Davenport, and A. R. Malo, "A comparison of the vegetation response to rainfall in the Sahel and East-Africa, using normalized difference vegetation index from Noaa Avhrr," Climatic Change. 17, 209-241, (1990) [doi:10.1007/BF00138369].

[26] C. J. Tucker, H. E. Dregne, and W. W. Newcomb, "Expansion and contraction of the Sahara Desert from 1980 to 1990," Science. 253, 299-300, (1991) [doi: 10.1126/science.253.5017.299].

[27]E. Weiss, S. E. Marsh, and E. S. Pfirman, "Application of NOAA-AVHRR NDVI time-series data to assess changes in Saudi Arabia's rangelands," Int J Remote Sens. 22, 1005-1027, (2001) [doi:10.1080/014311601300074540].

[28]E. Tarnavsky, S. Garrigues, and M. E. Brown, "Multiscale geostatistical analysis of AVHRR, SPOT-VGT, and MODIS global NDVI products," Remote Sens Environ. 112, 535-549, (2008) [doi:10.1016/j.rse.2007.05.008].

[29] M. E. Brown, Pinzon, J.E., Didan, K., MorisetteORISETTE, J.T and Tucker, C.J., "Evaluation of the consistency of long-term NDVI time series derived from AVHRR,SPOT-vegetation, SeaWiFS, MODIS, and Landsat ETM+ sensors," IEEE TGRS. 44, 1787-1793, (2006) [doi:10.1109/TGRS.2005.860205].

[30] C. Tucker, J. Pinzon, M. Brown, D. Slayback, E. Pak, R. Mahoney, E. Vermote, and N. El Saleous, "An extended AVHRR 8km NDVI dataset compatible with MODIS and SPOT vegetation NDVI data," Int J Remote Sens. 26, 4485-4498, (2005) [doi:10.1080/01431160500168686].

[31] M. Sivapalan, K. Takeuchi, S. W. Franks, V. K. Gupta, H. Karambiri, V. Lakshmi, X. Liang, J. J. McDonnell, E. M. Mendiondo, P. E. O'Connell, T. Oki, J. W. Pomeroy, D. Schertzer, S. Uhlenbrook, and E. Zehe, "IAHS decade on Predictions in Ungauged Basins (PUB), 2003-2012: Shaping an exciting future for the hydrological sciences," Hydro Sci J. 48, 857-880, (2003) [doi:10.1623/hysj.48.6.857.51421].

[32] T. Wagener, M. Sivapalan, and J. McDonnell, "Predictions in ungauged basins as a catalyst for multidisciplinary hydrology," EOS. 85, 451-457, 2004 [doi:10.1029/2004EO440003].

[33] C. Kummerow, W. Barnes, T. Kozu, J. Shiue, and J. Simpson, "The Tropical Rainfall Measuring Mission (TRMM) sensor package," J Atmos Oceanic Technol. 15, 809-817, (1998) [doi:10.1175/1520-0426(1998)015<0809:TTRMMT>2.0.CO;2]. 
[34] R. F. Adler, C. Kummerow, D. Bolvin, S. Curtis, and C. Kidd, "Status of TRMM monthly estimates of tropical precipitation," Meteorological Monographs. 29, 223223, (2003) [doi:10.1175/0065-9401(2003)029<0223:CSOTME>2.0.CO;2].

[35]E. Habib and W. F. Krajewski, "Uncertainty analysis of the TRMM groundvalidation radar-rainfall products: Application to the TEFLUN-B field campaign," $J$ Appl Meteorol. 41, 558-572, (2002) [doi:10.1175/1520-0450(2002)041<0558: $\mathrm{UAOTTG}>2.0 . \mathrm{CO} ; 2]$.

[36] A. P. Barros, M. Joshi, J. Putkonen, and D. W. Burbank, "A study of the 1999 monsoon rainfall in a mountainous region in central Nepal using TRMM products and rain gauge observations.," Geophys Res Lett. 27, 3683-3686, (2000) [doi:10.1029/2000GL011827].

[37] Y. N. Chen, H. Zilliacus, W. H. Li, H. F. Zhang, and Y. P. Chen, "Ground-water level affects plant species diversity along the lower reaches of the Tarim river, Western China," J Arid Environ. 66, 231-246, (2006) [doi:10.1016/j.jaridenv.2005.11.009].

[38] Y. Shi, Assessment of Climate Shift from Warm-dry to Warm-wet in Northwest China. Beijing: Meteorology Press, (2003).

[39] Tarim-River, "http://www.britannica.com/EBchecked/topic/583578/Tarim-River".

[40]B. Duchemin, B. Berthelot, G. Dedieu, M. Leroy, and P. Maisongrande, "Normalisation of directional effects in 10-day global syntheses derived from VEGETATION/SPOT: II. Validation of an operational method on actual data sets," Remote Sens Environ. 81, 101-113, (2002) [doi: Pii S0034-4257(01)00337-6].

[41] B. N. Holben, "Characteristics of Maximum-Value Composite images from temporal Avhrr data," Int J Remote Sens. 7, 1417-1434, (1986) [doi: 10.1080/01431168608948945].

[42] SPOT VEGETATION, "http://www.vgt.vito.be/faq/faq.html".

[43] S. D. Prince and C. J. Tucker, "Satellite remote-sensing of rangelands in Botswana .2. Noaa Avhrr and herbaceous vegetation," Int J Remote Sens. 7, 1555-1570, (1986) [doi: $10.1080 / 01431168608948953]$.

[44] C. J. Tucker, "Maximum normalized difference vegetation index images for subsaharan Africa for 1983-1985," Int J Remote Sens. 7, 1383-1384, (1986) [doi: $10.1080 / 01431168608948941]$.

[45] A. S. Hope, W. L. Boynton, D. A. Stow, and D. C. Douglas, "Interannual growth dynamics of vegetation in the Kuparuk River watershed, Alaska based on the Normalized Difference Vegetation Index," Int J Remote Sens. 24, 3413-3425, (2003) [doi:10.1080/0143116021000021170].

[46] D. Stow, S. Daeschner, A. Hope, D. Douglas, A. Petersen, R. Myneni, L. Zhou, and W. Oechel, "Variability of the seasonally integrated normalized difference vegetation index across the north slope of Alaska in the 1990s," Int J Remote Sens. 24, 11111117, (2003) [doi:10.1080/0143116021000020144].

[47] L. Milich and E. Weiss, "GAC NDVI interannual coefficient of variation (CoV) images: ground truth sampling of the Sahel along north-south transects," Int $J$ Remote Sens. 21, 235-260, (2000) [doi:10.1080/014311600210812].

[48] S. M. Vicente-Serrano, J. M. Cuadrat-Prats, and A. Romo, "Aridity influence on vegetation patterns in the middle Ebro Valley (Spain): Evaluation by means of AVHRR images and climate interpolation techniques," J Arid Environ. 66, 353-375, (2006) [doi:10.1016/j.jaridenv.2005.10.021].

[49]ZG. Bai, DL Dent, and ME. Schaepman, "Quantitative global assessment of land degradation and improvement: pilot study in North China. Report 2005," ISRIC World Soil Information, Wageningen, (2005). 
[50] Y. Chen, K. Takeuchi, C. Xu, Y. Chen, and Z. Xu, "Regional climate change and its effects on river runoff in the Tarim Basin, China," Hydrol Process. 20, 2207-2216, (2006) [doi:10.1002/hyp.6200].

[51] M. K. Woo, Z. N. Yang, Z. J. Xia, and D. Q. Yang, "Streamflow processes in an alpine permafrost catchment, Tianshan, China," Permafrost Periglac. 5, 71-85, (1994) [doi: 10.1002/ppp.3430050202].

[52]D. M. Lawrence and A. G. Slater, "A projection of severe near-surface permafrost degradation during the 21st century," Geophysical Research Letters. 32, L24401, (2005) [doi:10.1029/2005GL025080].

[53] D. A. Robinson, C. S. Campbell, J. W. Hopmans, B. K. Hornbuckle, S. B. Jones, R. Knight, F. Ogden, J. Selker, and O. Wendroth, "Soil moisture measurement for ecological and hydrological watershed-scale observatories: A review," Vadose Zone Journal. 7, 358-389, (2008) [doi: 10.2136/Vzj2007.0143].

[54]H. S. Srivastava, P. Patel, Y. Sharma, and R. R. Navalgund, "Large-Area Soil Moisture Estimation Using Multi-Incidence-Angle RADARSAT-1 SAR Data," Ieee TGRS. 47, 2528-2535, (2009) [doi: 10.1109/Tgrs.2009.2018448].

[55] L. Wang, J. Wen, T. Zhang, Y. Zhao, H. Tian, X. Shi, X. Wang, R. Liu, J. Zhang, and $\mathrm{S}$. Lu, "Surface soil moisture estimates from AMSR-E observations over an arid area, Northwest China," Hydrol Earth Syst Sci Discuss. 6, 1055-1087, 2009 [doi:10.5194/hessd-6-1055-2009].

[56] M. S. Moran, C. D. Peters-Lidard, J. M. Watts, and S. McElroy, "Estimating soil moisture at the watershed scale with satellite-based radar and land surface models," Can. J. Remote Sensing. 30, 805-826, (2004).

[57] Q. Zhou, B. Li, and A. Kurban, "Trajectory analysis of land cover change in arid environment of China," Int J Remote Sens. 29, 1093-1107, (2008) [doi: 10.1080/01431160701355256].

[58] Q. M. Zhou, B. L. Li, and A. Kurban, "Spatial pattern analysis of land cover change trajectories in Tarim Basin, northwest China," Int J Remote Sens. 29, 5495-5509, (2008) [doi:10.1080/01431160802060938].

[59] Y. F. Tong, C. X. Wu, and B. Y. Wang, "Relations on population growth, water resource and desert in Tarim River area of Xinjiang province," Population Journal. 37-40, (2006).

[60] Y. Chen, Z Xu, "Plausible impact of global climate change on water resources in the Tarim River Basin," Science in China (Earth Sciences). 48, 65-73, (2005) [doi:10.1360/04yd0539].

[61]F. Xie, W. Mao, J. Zhang, Q. Gao, Y. Shen, J, Wang, and S. Wang. "Analysis of Streamflow from Four Source River to Mainstream of the Tarim River, 2005," Journal of Glaciology and Geocryology. 29, 559-569 (2007).

[62] J. Zhang, J. Wang, H. Ma, Q. Gao, Y. Shen, J. Wang, W. Mao, W. Gong and S. Wang. "Streamfiow variations of four source streams to mainstream of Tarim River, Xinjiang and water transportation in 2006," Journal of Glaciology and Geocryology. 30, 569-577, (2008).

[63] R. Ragab and C. Prudhomme, "Climate change and water resources management in arid and semi-arid regions: Prospective and challenges for the 21st century," Biosystems Engineering. 81, 3-34, (2002) [doi:10.1006/bioe.2001.0013]. 